\title{
Licenciatura em Educação do Campo na Universidade Federal do Espírito Santo: trajetória, organização e funcionamento
}

\author{
Charlinni da Rocha Leonarde ${ }^{1}$ \\ Orcid: https://orcid.org/0000-0003-0760-9348 \\ Renata Duarte Simões ${ }^{1}$ \\ Orcid: https://orcid.org/0000-0002-8378-2890 \\ Alexandro Braga Vieira ${ }^{1}$ \\ Orcid: https://orcid.org/0000-0001-5952-0738 \\ Jacyara Silva de Paiva ${ }^{1}$ \\ Orcid: https://orcid.org/0000-0002-2917-7673
}

\section{Resumo}

0 artigo busca compreender a história de criação da licenciatura em educação do campo na Universidade Federal do Espírito Santo. 0 curso objetiva formar profissionais da educação para atuação por áreas de conhecimento (linguagens e ciências humanas e sociais) para a segunda etapa do ensino fundamental e para o ensino médio, partindo do princípio de que educação do campo é uma construção coletiva como prática de diálogo libertador, em cujo processo educandos e professores constroem-se e são construídos como sujeitos históricos autônomos e capazes de ler o mundo. Para tanto, o artigo recorre a autores que vêm se dedicando a produzir conhecimentos sobre a educação do campo e a formação de professores para atuação em escolas campesinas. Como aporte teórico-metodológico, utiliza os pressupostos da pesquisa histórica, realizando análise de documentos estruturantes do curso e realização de entrevistas com profissionais da universidade que trabalharam na elaboração de proposta de formação. Como resultados, o estudo evidencia que a educação do campo se coloca como uma luta histórica pelos movimentos sociais; que a Universidade Federal do Espírito Santo buscou constituir ações e negociações para a implantação do curso; e que a formação de professores para atuação em escolas do campo é uma ação que, se contemplada, impacta no direito à educação para os grupos sociais que lidam e vivem da terra.

\section{Palavras-chave}

Educação - Educação do Campo - Formação de professores.

1- Universidade Federal do Espirito Santo, Vitória, ES, Brasil.

Contatos: charlinni.r@hotmail.com; renasimoes@hotmail.com; allexbraga@hotmail.com; jacyarapaiva@hotmail.com

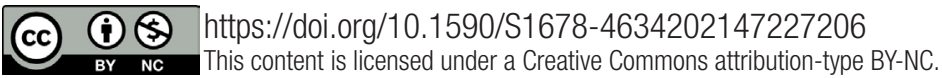




\section{Licentiate degree in Rural Education at the Federal University of Espírito Santo, Brazil: trajectory, organization and functioning*}

\section{Abstract}

The article seeks to understand the history of creating a teaching degree in rural education at the Federal University of Espirito Santo, Brazil. The course aims to train education professionals to work in areas of knowledge (languages and human and social sciences) for the second stage of elementary education and for secondary education, based on the principle that rural education is a collective construction as a practice of a liberating dialogue, in the process of which students and teachers construct themselves and are constructed by others as autonomous historical subjects capable of reading the world. To this end, the article uses authors who have been dedicated to producing knowledge about rural education and the training of teachers to work in rural schools. As a theoreticalmethodological approach, it uses the assumptions of historical research, performing analysis of the course's structuring documents and conducting interviews with university professionals who worked on the preparation of the training proposal. As a result, the study shows that rural education is a historic struggle for social movements; that the Federal University of Espirito Santo sought to constitute actions and negotiations for the implementation of the course; and that the training of teachers to work in rural schools is an action that, if contemplated, impacts the right to education for the social groups that deal with and live on the land.

\section{Keywords}

Education - Rural education - Teacher training.

\section{Introdução}

No Brasil, durante a década de 1960, foram implantados os primeiros movimentos por uma educação de qualidade no campo: a Escola Família Agrícola (EFA) e a Casa Familiar Rural (CFR). 0 conjunto formado pela EFA e a CFR passou a ser denominado "Centros Familiares de Formação por Alternância" (CEFFA). As primeiras experiências com a pedagogia da alternância surgiram no Espírito Santo, em 1969, no município de Anchieta, com parceria entre a Itália e o Brasil (NASCIMENTO, 2009).

A pedagogia da alternância surgiu como pretensão de ser uma alternativa ao ensino tradicional e constitui-se como uma proposta educativa que alterna tempos-espaços de estudo na escola e momentos de formação nas comunidades de origem dos educandos. Essa articulação ocorre por meio da apropriação de conhecimentos no espaço escolar e a realização de pesquisas de campo, favorecendo a relação entre teoria e prática na formação dos estudantes. 
Desde o início defendeu-se uma escola que fosse de natureza familiar e assumida pelas famílias residentes no campo, com uma proposta de contextualização da educação que unisse teoria e prática. Segundo Nosella (2012), pensar sobre a pedagogia da alternância no Espírito Santo é fortalecer as lutas coletivas por escolas públicas de qualidade para aqueles que vivem no campo, ampliando assim o conceito de educação para todos.

A partir dessas ações educativas voltadas aos povos campesinos, emergiu a necessidade de investimento na criação de cursos de formação de professores para fortalecimento da educação do campo, tendo como viés a pedagogia da alternância. Como uma das iniciativas, o Movimento dos Trabalhadores Rurais Sem Terra (MST) buscou, junto à Escola de $1^{\circ}$ e $2^{\circ}$ Graus "Santo Antônio", localizada em São Mateus/ES, habilitar os professores/monitores das escolas de assentamento, ofertando o curso de magistério (anos iniciais) em nível de ensino médio. As aulas foram iniciadas em julho de 1995, no Centro Integrado de Desenvolvimento e Assentamento de Pequenos Agricultores (CIDAP).

0 surgimento "[...] das primeiras turmas do curso de magistério fizeram com que o Setor de Educação do MST percebesse a potencialidade política e pedagógica do processo de formação sistemática de educadores” (MARQUES, 2010, p. 63), dando início a uma militância pela educação do/no campo.

Em 1987, o MST organizou o primeiro Encontro Nacional de Professores de Assentamento no Município de São Mateus/ES. Nesse encontro foi discutida a constituição de um curso em nível superior, o curso de pedagogia da terra. Essa denominação foi pensada por apresentar significados próprios e capazes de atender à identidade cultural dos povos do campo, sendo que uma das reivindicações dos movimentos sociais era a construção de um currículo que se aproximasse da realidade campesina e que atendesse às necessidades dos sujeitos do/no campo.

Assim, em 1990, o Coletivo Nacional de Educação pôs em prática a sistematização da proposta de educação do MST, mas, somente em 1999, criou-se a primeira turma do curso pedagogia da terra no Espírito Santo, para atender aos educadores e às educadoras da reforma agrária, com convênio entre o Programa Nacional de Educação na Reforma Agrária (PRONERA), o Instituto Nacional de Colonização e Reforma Agrária (INCRA) e a Universidade Federal do Espírito Santo (PEZZIN; FOERSTE, 2012).

[...] a articulação nacional do MST e os cursos de Pedagogia da Terra em nosso Estado fortaleceram a luta pela Educação do Campo no país, sendo estes marcos relevantes e fertilizadores das práticas que hoje ocupam os espaços tempos formativos de professores do campo em nosso Estado. (JESUS, 2014, p. 161).

A partir dessa iniciativa, outras propostas foram criadas em nível de pós-graduação até culminar na criação da licenciatura em educação do campo, ofertada pela Universidade Federal do Espírito Santo (UFES), a partir do ano de 2014. Tomando esse curso como foco de análise, direcionaremos nossas atenções, neste texto, para compreender como se configurou historicamente o referido curso, identificando e analisando os fatos que antecedem essa criação e a trajetória percorrida desde a elaboração do projeto por seus idealizadores até a implantação da proposta. 


\section{Pressupostos teóricos sobre a formação de professores na educação do campo}

De acordo com Foerste (2008), a educação do campo é uma construção coletiva como prática de diálogo libertador, em cujo processo educandos e professores constroemse e são construídos como sujeitos históricos autônomos e capazes de ler o mundo. Nesse contexto, o educador desempenha um papel fundamental no fomento à cultura, na formação dos sujeitos e na organização político-social.

No campo, falar em educação não implica apenas tratar das conquistas de espaço físico para a escola, mas também da valorização do campo e de um espaço onde os envolvidos são instigados a se posicionarem criticamente em relação à sociedade capitalista e a serem sujeitos da sua história, mas sujeitos coletivos, vinculados a uma luta social (CALDART, 2004).

Klein (2013, p. 35) aponta que a luta por uma escola de qualidade no campo deve ser refletida por um projeto de educação que considere os sujeitos que habitam nesses espaçostempos e suas especificidades. A autora destaca que "[...] é momento de desconstruir o paradigma hegemônico que carrega a educação ofertada aos diversos sujeitos do campo".

Essas ações contribuem para a reflexão sobre uma escola emancipatória/libertadora, que não exclui nem hierarquiza sujeitos. Para Freire (1987, p. 10), essa escola realiza o trabalho pedagógico ciente de que “[...] a prática da liberdade só encontrará adequada expressão numa pedagogia em que o oprimido tenha condições de, reflexivamente, descobrir-se e conquistar-se como sujeito da sua própria destinação histórica".

Desse modo, quando refletimos sobre formação docente em contextos campesinos, logo pensamos em uma formação comprometida com a transformação, consciente da realidade escolar, da complexidade e dos desafios que emergem desse/nesse campo. No entanto, muitos professores que atuam nas escolas do campo não foram capacitados para lidar com as peculiaridades da região, tendo dificuldades de promover diálogos entre os conhecimentos curriculares e aqueles que emanam dos territórios de onde provêm os estudantes.

Segundo Arroyo, Caldart e Molina (2008), no campo se concentra o maior número de professores leigos, são mínimas as condições de formação no meio rural e, de modo geral, os programas de formação de professores, incluindo os cursos de magistério e os cursos superiores, não tratam da questão do campo, nem mesmo nas regiões em que grande parte dos professores seguramente irá trabalhar, ou, se o fazem, é no sentido de reproduzir preconceitos e abordagens pejorativas. Nas universidades, os currículos dos cursos de formação baseiam-se unicamente no contexto urbano e excluem da discussão, da problematização e da construção de metodologias os contextos e grupos minoritários, tais como as iniciativas de educação popular, os movimentos sociais, o meio rural etc. (RIBEIRO; MARIN, 2009).

A partir da problemática exposta e em atendimento às reivindicações e às demandas educacionais das comunidades campesinas e dos movimentos sociais, o que se deu com muita luta, propostas de implementação de cursos de formação de professores para atuação em escolas do campo ganharam visibilidade em debates engendrados em espaços acadêmicos e políticos. No Espírito Santo, a licenciatura em educação do campo também 
teve sua origem a partir de lutas e reivindicações de movimentos sociais que compreendem o direito a uma educação emancipatória para os povos campesinos, considerando a formação dos professores como um dos pilares dessa conquista.

\section{Metodologia}

Optamos por empregar a pesquisa histórica de cunho qualitativo, buscando entender o passado através do presente. Bloch (2002) defende a inseparabilidade do presente e do passado, afirmando que o historiador pesquisa o passado a partir do seu tempo - do tempo presente - e do seu espaço social. Assim, entendemos que a história da educação do tempo presente modifica a história da educação do tempo passado.

Como procedimentos metodológicos, selecionamos a análise de documentos e a realização de entrevistas não estruturadas com sujeitos envolvidos com a criação do curso. No primeiro momento, analisamos o Projeto Político Pedagógico da Licenciatura em Educação do Campo e o documento Tempo-Comunidade e Tempo-Universidade, esse último elaborado pelos docentes que atuaram nos dois primeiros anos de funcionamento do curso (UNIVERSIDADE FEDERAL DO ESPÍRITO SANTO, 2014).

Nunes e Carvalho (2005, p. 29) destacam a importância das fontes para os historiadores da educação, argumentando que “[...] dependem, nas suas investigações, não apenas das questões formuladas dentro de certas matrizes teóricas, mas também dos materiais históricos com que podem contar". Nesse sentido, os documentos escritos (oficiais ou não oficiais) se constituem como matéria prima do historiador, aquilo de que ele se vale para fazer história (LOPES; GALVÃO, 2001).

A partir da análise dos documentos, é possível compreender o valor que a educação tem na formação dos sujeitos. A construção do projeto político-pedagógico de um curso significa a oportunidade de aproximação da comunidade, dos pais, dos professores e da equipe técnica em busca de resultados que mostrem essa importância (VEIGA, 1995).

$\mathrm{Na}$ licenciatura em educação do campo, o projeto político-pedagógico tem como objetivo a formação de professores para o exercício da docência nas escolas do campo, por meio da "[...] operacionalização do planejamento escolar, em um movimento constante de reflexão-ação-reflexão" (BETINI, 2005, p. 38).

Segundo o projeto político-pedagógico (PPP) da licenciatura em educação do campo da UFES, o curso visa suprir a necessidade de educação no/para o campo, por meio de processos de reflexão sobre novos paradigmas educacionais; compor currículos mais acessíveis, recursos didáticos adequados, materiais pedagógicos contextualizados para a elaboração coletiva de conhecimentos críticos e dialógicos; constituir alternativas a um projeto de sociedade que não atende às expectativas da população que se encontra no campo. Para tanto, ao buscar inspiração em Fazenda (1979), sinaliza que a organização desse projeto tem como base teórica-conceitual a multi, inter e transdisciplinaridade na superação dos limites das disciplinas.

Logo, podemos afirmar que o PPP está comprometido com um projeto de mudança na sociedade e na vida das pessoas, colocando a escola como um de seus atores, ao reconhecer a sua importância. Conforme dito por Veiga $(1995$, p. 13), “[...] é político no sentido de compromisso com a formação do cidadão para um tipo de sociedade". 
No segundo momento, realizamos as entrevistas não estruturadas para a coleta de dados, pois, segundo Moreira e Caleffe (2008, p. 168), “[...] nos possibilitam maior liberdade para fazer perguntas sem estabelecer previamente uma sequência”. Os entrevistados reconstituem a história da elaboração de proposta do curso por meio de resgate seletivo de memória. Conforme apontado por Le Goff (1996), a memória coletiva faz parte das grandes questões das sociedades desenvolvidas e daquelas em vias de desenvolvimento, das classes dominantes e das classes dominadas, lutando todas pelo poder ou pela vida, pela sobrevivência e pela promoção.

Os entrevistados são dois professores/profissionais que participaram da criação da licenciatura em educação do campo da UFES, campus Goiabeiras, por assumirem certo protagonismo na elaboração da proposta encaminhada ao Ministério da Educação e nas discussões no âmbito da universidade, trazendo as demandas dos movimentos sociais, dada a implicação que estas possuem com os mesmos. Nosso propósito foi obter informações a partir dos respondentes, captar descrições das situações e elucidar detalhes do evento. A análise dos dados se deu de forma qualitativa, em que buscamos contextualizar a educação do campo no Espírito Santo, considerando os aspectos relevantes que contribuíram para o surgimento de uma licenciatura específica para formação de docentes para as escolas campesinas.

As entrevistas foram previamente agendadas, por meio de convite realizado por e-mail. Inicialmente foram apresentados os objetivos da pesquisa e esclarecidos os procedimentos para a realização da coleta de dados, e também foram recolhidas as assinaturas do termo de consentimento livre e esclarecido. Assim, as entrevistas, realizadas em março e abril de 2018, foram organizadas em espaços da Universidade Federal do Espírito Santo, buscando garantir um ambiente propício para a gravação de áudio e de modo a reduzir possíveis interferências externas. As narrativas elaboradas, a partir desses encontros, nos ajudaram a pensar aspectos históricos, sociais e políticos que permeiam a educação do campo e o cenário de criação do curso em questão.

Consideramos que as fontes narrativas são muito importantes para investigação histórica, podendo ser utilizadas como ferramenta de pesquisa e ensino em uma via de mão dupla. 0 papel do pesquisador, ao analisar um evento histórico, não é de julgar, mas sim de compreender: "[...] uma palavra, em suma, domina e ilumina os nossos estudos: compreender... através da compreensão e não do julgamento que o historiador deve analisar os fatos" (BLOCH, 2002, p. 163). Na perspectiva de compreender é que desenvolvemos esta pesquisa.

\section{A licenciatura em educação do campo na UFES}

0 curso de licenciatura de educação do campo da Universidade Federal do Espírito Santo, ofertado a partir de 2014, surgiu como parte de uma política nacional de educação do campo e é o resultado de um esforço conjunto do Ministério da Educação (MEC), Secretaria de Educação Superior (SESU), Secretaria de Educação Profissional e Tecnológica (SETEC), Secretaria de Educação Continuada, Alfabetização, Diversidade e Inclusão (SECADI) e dos movimentos sociais. 
Para remontar a constituição da licenciatura plena em educação do campo da UFES, é preciso um retorno no tempo e na história, para rememorar as primeiras iniciativas que deram sustentação ao curso em tela. Nesse cenário, ganha destaque o curso pedagogia da terra, também realizado pela UFES, em parceria com várias instituições sociais, entre as quais o MST.

Surgido na década de 1990, o curso pedagogia da terra deu início à formação de professores do campo pelo Brasil. As primeiras turmas a inaugurarem a licenciatura tiveram suas aulas na Universidade Federal do Espírito Santo (UFES) e na Universidade Estadual de Mato Grosso (UNEMAT).

Na UFES, o curso de licenciatura plena em pedagogia para educadores e educadoras da reforma agrária - pedagogia da terra - teve 62 alunos e ocorreu no campus Goiabeiras/ Vitória, em parceria com o MST e com o Instituto Nacional de Colonização e Reforma Agrária (KLEIN, 2013). Posteriormente, foram estabelecidas parcerias com a Universidade Federal do Pará (UFPA), Universidade Federal do Rio Grande do Norte (UFRN) e Universidade Estadual do Rio Grande do Sul (UERGS).

Os cursos de pedagogia da terra surgiram da necessidade de formar professores com um perfil e identidade específica para atender aos povos do campo. "Esse foi o ponto de partida: de lá para cá, os cursos vivenciaram muitas conquistas e criaram outros desafios" (MOREIRA, 2010, p. 108).

A partir do curso pedagogia da terra, novas demandas foram surgindo, resultantes da relação que se estabeleceu entre a universidade e o Movimento dos Trabalhadores Rurais Sem Terra, partindo da premissa de que a educação do campo é um direito dos povos que ali vivem e um dever do Estado. Nesse viés, uma das justificativas para a criação de uma licenciatura em educação do campo foi pensar que se consegue, a um só tempo, ter a formalidade exigida para lecionar em uma escola no campo, com o conhecimento acumulado por ser daquele lugar, reduzindo as possibilidades de ter docentes que não entendem aquela forma de pensar (JESUS, 2014).

Cabe destacar que a proposta de pedagogia da terra é o sustentáculo, o "guardachuva" que abriga a discussão de uma proposta de educação elaborada coletivamente e, a partir dessa premissa, o curso de licenciatura em educação do campo foi sendo gestado e subjetivado como o lugar da ação, que abriga homens e mulheres que constituirão um corpo docente cuja tarefa é a de contribuir para a formação de sujeitos mais críticos (MARTINS, 2012).

A partir da criação do curso pedagogia da terra e de outras ações/reflexões constituídas, deu-se início à implantação do curso de licenciatura em educação do campo. Para tanto, formou-se uma equipe de professores a fim de pensar sobre o projeto junto aos movimentos sociais. Foram realizadas várias discussões para a criação desse curso de modo que viesse a atender aos anseios da população campesina no Estado.

[...] E aí, nós avançamos muito nas discussões com os movimentos sociais e no interior da universidade, dentro desta perspectiva de se criar uma licenciatura. 0 que acabou acontecendo foi que as discussões em outras universidades também fluíram de maneira parecida com a UFES, eu digo parecida porque não era nos mesmos moldes, por exemplo: Brasília estava propondo um 
curso de licenciatura muito parecido com o nosso curso de pedagogia da terra, e eles também procuravam tornar essas ofertas como uma coisa definitiva e não apenas eventual. E aí, de uma certa forma, fomos surpreendidos por um decreto do governo federal, que instituiu um novo curso de licenciatura chamado educação do campo. (Entrevistado 1, 2018).

Esse projeto nacional tinha como premissa a ideia de que era preciso criar um sistema educacional que trouxesse uma relevância social, a partir da construção de uma escola que valorizasse a forma integral e plena do sujeito do campo, ou seja, uma escola que contribuísse para a formação de cidadãos autônomos e cientes de seus direitos e deveres perante a sociedade.

Tal proposta educacional, que foi se desenhando em conjunto com as reivindicações do MST, fundamentou a criação da licenciatura em educação do campo, na UFES:

No caso da licenciatura em educação do campo, o que se conseguiu conquistar, até então, dava fôlego para o movimento continuar se organizando e fazendo sua pauta de articulação com as universidades na oferta da licenciatura. Eu entendo que o nosso envolvimento no processo, ele vem como resultado da caminhada que a gente vinha fazendo junto ao MST, principalmente, e o que se consegue no primeiro momento em termos de propostas de licenciatura como um curso que seria financiado pelo governo federal. [...] A expectativa é que as universidades passassem a assumir essa oferta, como uma oferta integrada às demais licenciaturas das universidades. (Entrevistado 2, 2018).

A criação do curso de licenciatura plena em educação do campo (PROCAMPO) foi solicitada ao Ministério da Educação (MEC), em 2008, mas o projeto precisou de adequações e apenas pela via de um edital publicado pelo próprio MEC, em 2012, que abria a possibilidade de várias universidades realizarem a oferta de cursos de formação para professores do campo em nível superior, é que a universidade, finalmente, conseguiu a autorização para que o curso fosse implantado.

A discussão entre a UFES e o MST, concernente à criação de um curso nos moldes pensados pelo movimento, não ocorreu de forma harmoniosa o tempo todo. Nas entrevistas, pudemos perceber críticas e certo preconceito em relação à concepção que o movimento social trazia, porque, além de ser uma proposta inovadora, ela mudava a lógica de funcionamento já instalada na universidade, sobretudo por desconstruir concepções de cursos fechados:

A organização mesmo da oferta foi muito debatida com a Prograd, ${ }^{2}$ de maneira que a cada organização que a gente fazia, descaracterizava o que a gente entendia que podia ser uma oferta feita para o campo, atendendo demandas que a gente já entendia serem demandas de formação do campo. E com isso, quando se tentava fazer uma organização diferente do quadradinho da universidade, a Prograd dizia: 'oh, não pode, porque nós não oferecemos 15 horas, nós não oferecemos 35 horas, vocês têm que entrar no padrão de 60 horas', porque isso evita problemas. (Entrevistado 2, 2018).

2- Prograd - Pró Reitoria de Graduação. 
Muitos dos conflitos entre os movimentos sociais e a universidade, na implementação do curso, nos levam a recordar que ainda existe um processo de massificação do ensino, consequência da abertura das escolas para todos, desvinculado de investimentos na qualidade do trabalho pedagógico direcionado para as camadas populares. Nessa lógica, é preciso formar para o mercado, sem a devida preocupação com a qualidade dos processos de ensino-aprendizagem, cenário retratado por Santos (2012, p. 83) quando argumenta:

A lógica tradicional não permite conceber o cotidiano dos estudantes como espaço de construção de saberes acadêmicos, pois o ensino tradicional, acostumado a negar qualquer forma de manifestação da classe trabalhadora, se vê ameaçado diante da ideia de conceder status de acadêmico aos conhecimentos que emergem do chão do povo camponês.

A proposta da licenciatura na UFES apontava para uma formação que viesse a transformar a realidade, desvelando o desconhecido e desconstruindo os preconceitos. Os movimentos sociais acreditam na organização da escola e dos processos educacionais caminhando juntos para reorganizar a sociedade.

É preciso lembrar que a busca por um processo educacional que reconheça as demandas trazidas pelo campo começou na década de 1960, com as experiências de educação popular e de luta pela reforma agrária. A Constituição Cidadã, aprovada em 1988, adotou o conceito de educação como um direito de todos e um dever do Estado e a Lei $n^{\circ}$ 9.394/96 consagrou esse reconhecimento quando trata da especificidade da educação do campo, em seu art. 28:

Art. 28. Na oferta de educação básica para a população rural, os sistemas de ensino promoverão as adaptações necessárias à sua adequação às peculiaridades da vida rural e de cada região, especialmente:

I - conteúdos curriculares e metodologias apropriadas às reais necessidades e interesses dos alunos da zona rural;

II - organização escolar própria, incluindo adequação do calendário escolar às fases do ciclo agrícola e às condições climáticas;

III - adequação à natureza do trabalho na zona rural. (BRASIL, 1996).

Apesar da garantia legal à educação pública, as escolas pouco mudaram. Isso serviu como um incentivo aos movimentos sociais para lutarem e cobrarem que as mudanças fossem efetivadas. Com isso, em 4 de dezembro de 2001, por meio do Parecer $n^{\circ}$ 36, foram estabelecidas as Diretrizes Operacionais para a Educação Básica nas Escolas do Campo e, no ano seguinte, efetivou-se a criação do Grupo de Trabalho Permanente de Educação no Campo (Resolução no 1/2002 do Conselho Nacional de Educação) (BRITO, 2011).

Em 2006, o Ministério da Educação abriu edital com oferta regular da licenciatura em educação do campo. Em 2009, por meio do Decreto $n^{\circ}$ 6.755, de 29 de janeiro, foi estabelecida a base para a formação de professores para a modalidade, mas, apenas em 2010, foi publicado o decreto regulamentando o credenciamento de universidades que então passariam a oferecer a referida licenciatura, em atendimento a todos os grupos que atuam na área rural. 
A UFES já tinha um processo de credenciamento, junto ao MEC, desde 2008. Esse projeto já enviado passou por adequações e foi reenviado em 2012. 0 decreto do governo incorporou políticas tais como acesso à universidade, formação dos gestores desses espaços educativos, merenda escolar, transporte, produção de materiais específicos, além do respeito à pedagogia da alternância (UNIVERSIDADE FEDERAL DO ESPÍRITO SANTO, 2013).

Ainda que o projeto tenha passado por adequações, o grupo compreendia que não podia abrir mão da pedagogia da alternância. Tê-la como base pedagógica certamente representava a vitória da ousadia do movimento social, significava ter conseguido passar por todo o processo burocrático que envolve a criação de um curso de nível superior com aprovação nas diversas instâncias. Essa vitória retratava também a capacidade de articular parcerias construídas nas mais diversas esferas.

Santos (2012, p. 84), ao tratar da concretude desse projeto, nos lembra que "[...] se os cursos não tivessem a organização dos tempos alternados, muitos dos que hoje acessam a universidade não teriam condições de fazê-lo dentro da atual conjuntura acadêmica". Trabalhar na pedagogia da alternância significa dar um mesmo peso ao conhecimento, ou seja, aqueles advindos das comunidades dos estudantes e os que compõem o corpus de conhecimento sobre os fundamentos da educação.

Também é importante lembrar a ressignificação do papel do professor que, nessa perspectiva, ensina e aprende simultaneamente (FREIRE, 1996). 0 professor participa dos processos de ensinar e aprender; torna-se parte da dinâmica diária das lutas de mulheres e homens do campo em favor de uma educação libertadora que reconhece os povos do campo como sujeitos de direito e de conhecimentos (SANTOS, 2012).

Em debate sobre a estrutura de funcionamento do curso, o grupo de professores iniciadores elaborou uma proposta que pudesse atender às necessidades dos povos campesinos:

Pensamos em um curso que fosse itinerante, pensamos que podia acontecer aqui, mas ele não podia se restringir à sala de aula. Então eu entendo que a gente teve uma construção muito bonita no processo, o que a gente almejava era muito do âmbito solidário, da construção coletiva do fazer acontecer coisas que a gente sabe que no campo ganham outra dimensão, na medida em que você pode impactar as famílias, quando se pensa na perspectiva da alternância. (Entrevistado 2, 2018).

A partir dos relatos dos entrevistados, é possível compreender que o grupo sentia a necessidade de pensar em processos de ensino que ocorressem por meio da alternância. Essa experiência objetiva assegurar a especificidade da formação na diversidade sociocultural e o direito universal dos povos do campo à educação pública, de qualidade, laica, socialmente referenciada, pois são adquiridos conhecimentos que favorecem diálogos interculturais entre a universidade e o campo.

É na vinculação do conhecimento escolar com a ambiência familiar que eles refletem sobre seu meio e elaboram seus marcos de referências identitárias, possibilitando-lhes a manutenção do contato com as múltiplas dimensões dessa realidade e os auxiliando na formação de uma identidade cultural coletiva que ultrapassa barreiras geográficas de seus espaços de pertencimentos. (CALIARI, 2012, p. 39). 
A licenciatura plena em educação do campo da UFES destaca-se por buscar o envolvimento conjunto entre a teoria e a prática. Assim, ela é configurada para formar profissionais para atuação no ensino fundamental II e no ensino médio, por áreas de conhecimento e não por disciplinas, o que se consolidou, na época, como uma das experiências pioneiras, além da formação em alternância no ensino superior, conforme descrição do projeto político-pedagógico:

O Projeto da Licenciatura em Educação do Campo proposto pelo MEC prevê habilitar professores para a docência multidisciplinar num currículo organizado em quatro áreas do conhecimento: Linguagens; Ciências Humanas e Sociais; Ciências da Natureza e Matemática; Ciências Agrárias. A proposta desta licenciatura na UFES, em sua primeira etapa (até o ano de 2016), ofertará aos estudantes, a opção de escolha em duas destas áreas: CIÊNCIAS HUMANAS E SOCIAIS (Geografia, História, Filosofia e Sociologia) E LINGUAGENS (expressão oral e escrita em Língua Portuguesa, Artes, Literatura e Educação Física). Cada estudante poderá optar pela habilitação em uma delas, para a qual será licenciado. (UNIVERSIDADE FEDERAL DO ESPÍRITO SANTO, 2013, p. 9).

Essa organização do curso para a formação de professores no campo por área de conhecimento e a pedagogia da alternância somam-se em uma importante proposta de atender às demandas dos povos campesinos. A prática da pedagogia da alternância vem se enraizando historicamente no Estado, sendo uma instância potencializadora para o surgimento do curso que viabiliza parcerias entre Estado, comunidade rural e movimentos rurais. Pensar a formação docente, em alternância, implica uma construção coletiva comprometida com a realidade das famílias campesinas.

A educação do campo trata de uma educação que valoriza a unidade familiar e a vida dos povos do campo, assim como o respeito à cultura e ao trabalho, de modo a priorizar as relações sociais que se estabelecem no contato e no cuidado com a terra, rompendo a visão do campo como espaço do agronegócio. 0 acesso ao ensino superior para os sujeitos do campo, na perspectiva da educação do campo, segundo Fernandes (2009, p. 15), “[...] é mais uma ferramenta para a formação de cidadãos capazes de transformar a sociedade e a si mesmos e é pensado a partir do diálogo com a realidade mais ampla”.

No projeto político-pedagógico do curso de pedagogia, até então existente na UFES, não havia qualquer menção à educação do campo ou a uma educação pautada em metodologia específica que reconheça a forma de organização desse segmento populacional. Com a criação da licenciatura em educação do campo, encontramos o viés almejado pelos movimentos sociais e pelos povos campesinos, ou seja, uma formação que pense as especificidades de quem está nesse território. 0 curso de pedagogia também foi afetado por tal iniciativa, pois, mesmo que de forma tímida, passou a ofertar uma disciplina optativa no âmbito da educação do campo.

Sobre a licenciatura plena em educação do campo, espera-se a formação de educadores a partir dos seguintes objetivos:

a) Formar educadores e educadoras para atuação específica junto às populações que trabalham e vivem no e do campo, no âmbito das diferentes etapas e modalidades da Educação Básica e com 
condições de promover uma diversidade de ações pedagógicas que colaborem para a garantia do direito à educação de qualidade no campo e como ferramenta de desenvolvimento social.

b) Desenvolver estratégias de formação para a docência multidisciplinar em uma organização curricular por áreas do conhecimento nas escolas do campo.

c) Contribuir na construção de alternativas de organização do trabalho escolar e pedagógico que permitam a expansão da educação básica no e do campo, com a qualidade exigida pela dinâmica social em que seus sujeitos se inserem e pela histórica desigualdade que sofrem.

d) Estimular na UFES e junto aos demais parceiros da implementação deste projeto de Licenciatura ações articuladas de ensino, de pesquisa e de extensão voltadas para demandas da Educação do Campo. (UNIVERSIDADE FEDERAL DO ESPÍRITO SANTO, 2013, p. 9).

A licenciatura em educação do campo objetiva mudança real. Os militantes que lutam por implantar esse projeto acreditam que, se existe um grupo de opressores e um grupo de oprimidos, isso foi criado pela sociedade em que vivem esses oprimidos que, por não terem outra referência, aderem às ideias do opressor. No entanto, a educação não pode ser pensada apenas pela perspectiva do opressor, é preciso ter um novo paradigma. Isso pode ser conseguido com uma forma de educar que pensa a vida, o cuidado com o meio ambiente, a sociabilidade entre as pessoas e tenha, como eixo central, um novo projeto de desenvolvimento com justiça social (FREIRE, 1987).

No que diz respeito à organização, o curso segue as determinações do Parecer CNE/ CEB $n^{\circ} 1$, de $1^{\circ}$ de fevereiro de 2006, ou seja, é organizado em alternância entre Tempo/ Espaço Escola-Curso (TE) e Tempo/Espaço Comunidade-Curso (TC), articulando-se com a realidade e a educação das populações do campo (SILVA, 2013). A dinâmica da alternância, que o curso propõe, é de que o educando se compreenda nesses espaços e tempos de forma integral e humanística, para incitar transformações educativas.

A alternância da licenciatura em educação do campo estrutura-se em três dimensões. A primeira está pautada na formação humana, que objetiva a superação da escola capitalista; desse modo, entendemos que a alternância do curso assume uma práxis contrahegemônica, articulando a produção da vida e do conhecimento. A segunda concepção diz sobre as relações sociopolíticas e culturais, fazendo com que os educandos sejam capazes de estabelecer um novo projeto de sociedade e de inserção nas relações sociais. A terceira dimensão destaca as relações de produção de conhecimento (UNIVERSIDADE FEDERAL DO ESPÍRITO SANTO, 2013).

Quanto à previsão de dias letivos, organiza etapas presenciais no ambiente da universidade, conforme os demais cursos, e etapas que devem ser cumpridas no ambiente em que vive o estudante. Isso significa tempos diferentes do setor urbano. Os meses de janeiro e julho são aqueles em que o aluno deve estar na universidade presencialmente, além dos encontros mensais de três dias. Ali, ele deverá participar de aulas práticas e teóricas. Também deve exercitar a capacidade de auto-organização, por meio do trabalho em grupo, resolução de exercícios, leituras, além das atividades culturais. Cada aluno é responsável pela organização do seu tempo de estudo nos momentos em que não está em aula com os professores e colaboradores (UNIVERSIDADE FEDERAL DO ESPÍRITO SANTO, 2013).

No Tempo-Comunidade, o aluno prepara e realiza atividades tais como: pesquisa sobre a realidade, registro dessas experiências, implementação de ações pedagógicas, 
vivências que possibilitem a partilha de conhecimentos e desenvolvimento de projetos de aprendizagem em seus municípios de origem. A definição das atividades que serão desenvolvidas é orientada nos meses em que o aluno está na universidade presencialmente, ou seja, ele volta para casa com tarefas e prazos para serem cumpridos no período em que está na comunidade. Essa forma de organização permite que o aluno não perca suas referências com o lugar em que vive, possibilitando que ele participe dos desafios que ainda permeiam uma melhor compreensão da necessidade de ter educadores no campo comprometidos com outra forma de educar.

Nessa perspectiva, a realização do Tempo-Comunidade na licenciatura é mediada por três elementos fundamentais, entre as disciplinas escolares e o meio socioprofissional, sendo eles: Plano de Estudo (PE), Caderno da Realidade (CR) e o Seminário Integrador (SI).

O Plano de Estudo (PE) é elaborado pelo aluno e ocupa um papel central em que, por meio da pesquisa da realidade, promove-se o diálogo entre o saber popular e o saber científico. Esse plano é constituído de questões, tendo por base a realidade objetiva dos estudantes, sendo ligadas às suas realidades cotidianas. Ainda como parte do processo de mediação que ocorre no decorrer do PE, adota-se um valioso mecanismo que é o Caderno da Realidade (CR). Esse caderno segue o aluno durante todo o curso. Nele registra-se toda a trajetória escolar que são as principais questões discutidas no PE [...]. Nesse sentido, a execução do PE com o desenvolvimento da pesquisa, a coleta de dados, as análises e as reflexões, são todas registradas no caderno de Realidade que também pode ser denominado de Memorial ou Livro de Vida. Após o estudo da realidade, concretizado por meio do plano de Estudo, o aluno elabora suas sínteses que serão socializadas em um momento denominado de 'A Colocação Comum' com o propósito de elaborar suas antíteses (UNIVERSIDADE FEDERAL DO ESPÍRITO SANTO, 2014). ${ }^{3}$

Outro destaque desse curso é a prática da auto-organização. 0 curso propõe que os educandos utilizem a autogestão para amadurecimento e autonomia a fim de lidar com questões que extrapolem o espaço da sala de aula. "A partir dessa 'organicidade', os educandos se tornam responsáveis e sujeitos na gestão do processo de sua formação, ainda que em parte dele, além de contribuir na cooperação e construção do projeto pedagógico" (MST apud GONSAGA, 2009, p. 81).

0 curso também contribui para pensar um novo projeto de sociedade, usando como premissa a importância dos sujeitos do campo como protagonistas da educação nesse contexto. Para que isso ocorra, torna-se necessária a

[...] articulação entre os docentes envolvidos no curso; construção de momentos coletivos para socialização das ações e responsabilidades dos órgãos e universidade e a articulação entre todos os projetos de pesquisa e extensão que direta e indiretamente desenvolvem ações com os sujeitos do campo e da educação do campo. (UNIVERSIDADE FEDERAL DO ESPÍRITO SANTO, 2013, p. 105).

A licenciatura em educação do campo, mais do que formar professores para atuar nesses espaços-tempos, espera que esses profissionais compreendam a importância

\footnotetext{
3 - Documento orientador de realização do Tempo-Comunidade e Tempo-Universidade da Licenciatura em Educação do Campo da Universidade
} Federal do Espírito Santo, elaborado pelo corpo docente do curso. Disponível para consulta no Arquivo do Colegiado de Curso. 
de homens e mulheres lutarem criticamente para mudar uma lógica que os considera como peça da engrenagem da sociedade capitalista. Os movimentos sociais clamam pelo protagonismo que reconhece a importância da terra para a vida do homem. Nesse sentido, a licenciatura propõe que o docente tenha conhecimentos de como atuar na gestão escolar de escolas do campo, na docência e na articulação entre escola e movimentos sociais.

Ao responder sobre como o curso pensa a formação do educador do campo, os entrevistados acenam na direção da organização por áreas de conhecimento, que, no caso da licenciatura plena em educação do campo, campus Goiabeiras, são as áreas de linguagens e ciências humanas e sociais: "A nossa proposta para a grade curricular era de trabalhar até o terceiro período de forma conjunta e, a partir da formação conjunta, então, partir para as especificidades. Essa era nossa ideia, foi assim que foi pensado" (Entrevistado 2, 2018).

Ao organizar o currículo por área de conhecimento, a licenciatura em educação do campo busca a interação e o diálogo entre os saberes científicos e os saberes populares, estabelecendo relações com a forma de viver dos camponeses. Para garantir essa articulação entre os diferentes saberes, Souza et al. (2016) defendem a organização interdisciplinar do currículo, de forma que a reflexão teórico-conceitual possa fazer acontecer uma formação docente mais integrada com a vida e a realidade dos estudantes.

Então a formação desse profissional foi pensada de muitas formas, entendendo que o campo podia e pode dar uma oxigenada na universidade, na academia. Fizemos o possível a fazer com o percurso, acho que depende muito dos estudantes. No primeiro momento, tinha muita restrição do estudante que fosse vinculado ao campo. Nós não podemos fechar apenas a quem é do campo, nós temos que pensar que a interdependência de campo e cidade é uma compreensão que temos hoje, construindo outro paradigma. Se a gente restringir, podemos também excluir a oportunidade de pessoas que queiram se inserir nessa luta. (Entrevistado 2, 2018).

0 perfil dos candidatos às vagas no curso atende aos critérios estabelecidos pelo MEC a partir das demandas que foram identificadas, discutidas e definidas conjuntamente pelas entidades parceiras desse ministério no processo de implantação dos cursos. 0 objetivo aqui é de consolidação de uma ação afirmativa com preferência para os professores que já atuam nas escolas do campo e precisam ser qualificados para o exercício da docência com conhecimento dos instrumentais pedagógicos disponíveis. Além desses critérios, o candidato precisa fazer uma prova escrita que tem relação com a política desenvolvida no campo.

Apesar dos critérios estabelecidos para ingresso no curso e da criação do PPP para submissão ao MEC, o grupo de professores iniciadores da proposta da licenciatura entendia que esses aspectos poderiam ser modificados posteriormente, no transcorrer do curso:

A casa que nós queremos arrumada, vamos arrumá-la também durante, não vamos pensar que esta casa vai ser toda arrumada antes de começar não. Na medida em que formos construindo, a gente vai arrumando esta casa, ela vai ganhando novos contornos, ela vai ganhando novas cores que não tinham sido pensadas antes, e isso não é negativo na minha opinião. Este curso 
tem muito disso, elementos artesanais, compreende? É um tipo de artesanato que, a princípio, não se conhece todo antes de praticá-lo, antes de fazê-lo, e você vai aperfeiçoando à medida que os acontecimentos vão pedindo novas cores, novos moldes, novas formas. (Entrevistado 1, 2018).

Cabe destacar que a licenciatura em educação do campo na universidade é uma conquista recente e que ela se constrói diariamente, não é um curso pronto e dado, é um curso em processo de construção, que possibilita a descoberta de novos caminhos para a formação docente. A prova do compromisso com essa modalidade de educação está expressa nas diversas formações ofertadas ao logo desses anos, visando suprir uma carência por conhecimentos específicos para esses profissionais. Tanto é assim que, desde 2010, o Centro de Educação da UFES conta com o Grupo de Pesquisa Culturas, Parcerias e Educação do Campo (KLEIN, 2013), além de outros que emergiram após a criação da licenciatura plena em educação do campo.

Conforme Molina e Sá (2010, p. 43), o “[...] desafio pedagógico desta proposta é de criar um projeto educativo integral, coerente, que produza valores, convicções, visão de mundo, consciência organizativa, capacidade de ação, sentido pleno de ser humano". Nesse sentido, pensar a formação do educador do campo é compreender o curso como um facilitador na construção humana dos educadores em contextos campesinos, que se dá na relação do aluno com curso e com a realidade em que ele está inserido.

Para Caldart (2012), por ser fruto dos movimentos sociais que lutam pela reforma agrária, a educação do campo já contém um diferencial, que é o da luta por direitos que atendam aos anseios da classe trabalhadora por um mundo diferente. Isso faz com que essa educação seja incorporada ao imaginário daqueles que estão no campo por uma educação diferenciada, que pode se alastrar também para um projeto de educação de quem vive na cidade, em torno das suas concepções.

\section{Considerações finais}

As respostas encontradas neste trabalho nos ajudam a pensar que o curso de licenciatura em educação do campo tem, como proposta pedagógica, a concretização de uma política de educação do campo como direito humano e como instrumento de desenvolvimento social, objetivando formar educadores habilitados para atuarem na gestão de processos educativos nas escolas do campo e a desenvolver ações pedagógicas que visem à formação de sujeitos em uma perspectiva emancipatória e crítica, capazes de produzir enfrentamentos para questões inerentes à realidade na qual vivem.

A análise desse contexto nos leva a entender a educação do campo como um direito dos sujeitos campesinos e um dever do Estado, situação a ser consolidada pela via de várias políticas públicas, com destaque para a formação inicial e continuada de professores, para a mediação de conhecimentos comprometidos com a transformação social e a constituição de estudantes que reconheçam o campo como lugar de cultura, de existências, resistências e de produção de vida.

Tais investimentos ganham visibilidade no cenário nacional e acenam para diversos obstáculos que ainda precisam ser superados. Compreende-se que muitas dificuldades já 
foram sobrepujadas pelos organizadores do curso e pelos docentes que trabalham nessa licenciatura. No entanto, muitos outros desafios estão por vir em face de mudanças políticas e sociais que estão ocorrendo na sociedade brasileira e que reconfiguram investimentos no ensino superior público, na formação de professores para atuação em escolas do campo, na oferta de vagas e na qualidade de ensino nessas escolas.

Esse cenário, permeado por lutas, mas também resistências, reflete a importância de profícuos diálogos e interações entre a universidade, os movimentos sociais e os povos do campo, tendo como horizonte uma educação pública, laica e de qualidade para aqueles que lidam e vivem da terra, sujeitos de conhecimento e de direito.

\section{Referências}

ARROYO, Miguel Gonzalez; CALDART, Roseli Salete; MOLINA, Mônica Castagna. Por uma educação do campo. 3. ed. Petrópolis: Vozes, 2008.

BETINI, Geraldo Antonio. A construção do Projeto Político Pedagógico da Escola. Revista Educação, Espírito Santo do Pinhal, v. 1, n. 3, p. 38-44, jan./dez. 2005.

BLOCH, Marc. Apologia da história. Rio de Janeiro: Jorge Zahar. 2002.

BRASIL. Lei $n^{\circ}$ 9.394, de 20 de dezembro de 1996. Estabelece as diretrizes e bases da educação nacional. Brasília, DF: [s. n.], 1996. Disponível em: http://www.planalto.gov.br/ccivil_03/leis/19394.htm. Acesso em: 12 out. 2016.

BRITO, Rosa Maria. Formação superior dos educadores do campo: análise das propostas pedagógicas dos cursos do Pronera da UFPB. 2011. 135 f. Dissertação (Mestrado em Educação) - Universidade Federal do Espírito Santo, João Pessoa, 2011.

CALDART, Roseli Salete. Educação do campo. In: CALDART, Roseli Salete et al. (org.). Dicionário da educação do campo. Rio de Janeiro: Escola Politécnica de Saúde Joaquim Venâncio; São Paulo: Expressão Popular, 2012. p. 259-267.

CALDART, Roseli Salete. Por uma educação do campo: traços de uma identidade. In: ARROYO, Miguel G.; CALDART, Roseli; MOLINA, Mônica (org.). Por uma educação do campo. Petrópolis: Vozes, 2004. p. 147-158.

CALIARI, Rogério. A prática pedagógica da formação em alternância. In: MERLER, Alberto et al. (org.). Educação do campo: diálogos interculturais em terras capixabas. Vitória: UFES, 2012.

FAZENDA, Ivani C. Integração e interdisciplinaridade no ensino brasileiro: efetividade ou ideologia. São Paulo: Loyola, 1979.

FERNANDES, Flávia A. Um estudo de caso do curso de pedagogia da terra da Universidade Federal do Rio Grande do Norte. 2009. 131 f. Dissertação (Mestrado em Educação) - Universidade de Brasília, Brasília, DF, 2009. 
FOERSTE, Erineu. Discussões acerca do projeto político-pedagógico da educação do campo. In: FOERSTE, Erineu; SCHÜTZ-FOERSTE, Gerda Margit; DUARTE, Laura Maria Schneider (org.). Por uma educação do campo: projeto político-pedagógico da educação do campo. v. 6. Vitória: UFES; Brasília, DF: INCRA, 2008. p. $75-126$.

FREIRE, Paulo. Pedagogia da autonomia: saberes necessários à prática educativa. São Paulo: Paz e Terra, 1996.

FREIRE, Paulo. Pedagogia do oprimido. 17. ed. Rio de Janeiro: Paz e Terra, 1987.

GONSAGA, Eliana Aparecida. Pedagogia da terra: o curso de licenciatura em educação do campo de Minas Gerais. 2009. 119 f. Dissertação (Mestrado em Políticas Públicas, Movimentos Instituintes e Educação) Universidade Federal Fluminense, Niterói, 2009.

JESUS, Janine Gerke de. Sentidos da formação docente para a profissionalização: na voz do professor do campo. 2014. 365 f. Tese (Doutorado em Educação) - Universidade Federal do Espírito Santo, Vitória, 2014.

KLEIN, Sônia Francisco. Educação do campo: um estudo sobre cultura e currículo na Escola Municipal de Ensino Fundamental Crubixá - Alfredo Chaves - Espírito Santo. 2013. 225 f. Dissertação (Mestrado em Educação) - Universidade Federal do Espírito Santo, Vitória, 2013.

LE GOFF, Jacques. História e memória. Tradução Bernardo Leitão et al. 4. ed. Campinas: Unicamp, 1996. (Repertórios).

LOPES, Eliane Marta Teixeira; GALVÃO, Ana Maria de Oliveira. História da educação. Rio de Janeiro: DP\&A, 2001.

MARQUES, Tatyanne Gomes. Pedagogia da terra: significados da formação para educadores e educadoras do campo. 2010. 183 f. Dissertação (Mestrado em Educação) - Universidade Federal Minas Gerais, Belo Horizonte, 2010.

MARTINS, Fernando José. A pedagogia da terra: os sujeitos do campo e do ensino superior. Revista Educação, Sociedade e Culturas, Porto, n. 36, p.103-119, 2012. Disponível em: http://www.fpce.up.pt/ ciie/revistaesc/ESC36/ESC36_Fernando.pdf. Acesso em: 22 nov. 2016.

MOLINA, Mônica Castagna; SÁ, Laís Maria Borges de Mourão. Desafios e perspectivas na formação de educadores: reflexões a partir da licenciatura em educação do campo da Universidade de Brasília. In: SOARES, Leôncio et al. (org.). Convergências e tensões no campo da formação e do trabalho docente. Belo Horizonte: Autêntica, 2010. p. 369-388.

MOREIRA, Herivelto de; CALEFFE, Luiz Gonzaga. Metodologia de pesquisa para o professor pesquisador. Rio de Janeiro: Editora Lamparina, 2008.

MOREIRA, Saléte Maria Palharinni. Pedagogia da terra: uma análise do(s) processo(s) formativo(s). 2010. 117 f. Dissertação (Mestrado em Educação) - Universidade de Brasília, Brasília, DF, 2010. 
NASCIMENTO, Claudemiro Godoy do. Gestão democrática e participativa na pedagogia da alternância: a experiência da Escola Família Agrícola (EFA) de Goiás. Revista Faced, Salvador, n. 15, p. 163-178, jan./jul. 2009. DOl: http://dx.doi.org/10.9771/2317-1219rf.v14i15.2968. Disponível em: http://www.portalseer. ufba.br/index.php/entreideias/article/viewFire/2968/3525. Acesso em: 15 abr. 2015.

NOSELLA, Paolo. Prefácio. In: MELER, Alberto et al. (org.). Educação do campo: diálogos interculturais em terras capixabas. Vitoria: Edufes, 2012. p. 13-26.

NUNES, Clarice; CARVALHO, Marta Maria Chagas de. Historiografia da educação e fontes. In: GONDRA, José Gonçalves (org.) Pesquisa em história da educação no Brasil. Rio de Janeiro: DP\&A, 2005. p. 17-62.

PEZZIN, Josimara; FOERSTE, Irineu. 0 curso pedagogia da terra da Universidade Federal do Espírito Santo. In: MELER, Alberto et al. (org.). Educação do campo: diálogos interculturais em terras capixabas. Vitória: UFES, 2012. p. 124-142.

RIBEIRO, Gabriela Machado; MARIN, Elizara Carolina. Educação física escolar: a ação pedagógica e sua legitimação enquanto prática social na Escola Itinerante do MST. Movimento, Porto Alegre, v. 15, n. 4, p. 63-82, out./dez. 2009.

SANTOS, Silvanete Pereira. A concepção de alternância na licenciatura de educação do campo. 2012. 163 f. Dissertação (Mestrado em Educação) - Universidade de Brasília, Brasília, DF, 2012.

SILVA, Júlio Cézar Pereira da. A formação política do educador do campo: estudo do curso de licenciatura em educação do campo da Universidade de Brasília. 2013. 86 f. Dissertação (Mestrado em Educação) Universidade de Brasília, Brasília, DF, 2013.

SOUZA, Rosineide Magalhães de etal. (org.). Letramentos múltiplos e interdisciplinaridade na licenciatura em educação do campo. Brasília, DF: Decanato de Extensão; Universidade de Brasília, 2016.

UNIVERSIDADE FEDERAL DO ESPÍRITO SANTO. Documento tempo comunidade e tempo universidade: colegiado de curso de licenciatura plena em educação do campo. Vitória: UFES, 2014.

UNIVERSIDADE FEDERAL DO ESPÍRITO SANTO. Projeto político pedagógico do curso de licenciatura plena em educação do campo. Vitória: UFES, 2013. Disponível em: http://www.ce.ufes.br/sites/ce.ufes. br/files/field/anexo/PPC_LEC_0.pdf. Acesso em: 26 jan 2016.

VEIGA, IIma Passos Alencastro. Escola: espaço do projeto político-pedagógico. São Paulo: Papirus, 1995.

Recebido em: 08.08.2019

Revisado em: 11.12.2019

Aprovado em: 18.02.2020 
Charlinni da Rocha Leonarde é graduada em pedagogia pela Universidade Federal do Espírito Santo (UFES), atuou como bolsista do Programa Institucional de Iniciação Científica (PIBIC) com o projeto Formação de Professores: aspectos históricos em Educação do Campo.

Renata Duarte Simões é doutora e pós-doutora em história da educação e historiografia pela Universidade de São Paulo (USP). Professora adjunta do Centro de Educação da Universidade Federal do Espírito Santo e coordenadora adjunta do Programa de Pós-Graduação de Mestrado Profissional em Educação.

Jacyara Silva de Paiva é doutora em educação pela Universidade Federal do Espírito Santo. Professora adjunta do Departamento de Linguagens, Cultura e Educação da Universidade Federal do Espírito Santo.

Alexandro Braga Vieira é doutor e pós-doutor em educação pela Universidade Federal do Espírito Santo. Professor adjunto do Centro de Educação. Coordenador do Programa de PósGraduação de Mestrado Profissional em Educação e professor do Programa de Pós-Graduação em Educação da UFES. 